\title{
Análise de crescimento de Bixa orellana L. sob efeito da inoculação micorrízica e adubação fosfatada
}

\author{
BARBIERI, D.J. ${ }^{1}$; BRAGA, L.F. ${ }^{2 *}$; SOUSA, M.P. ${ }^{3}$; ROQUE, C.G. ${ }^{4}$ \\ ${ }^{1}$ Unidade de Ensino do Centro Estadual de Educação Profissional e Tecnológica - CEPROTEC, Canteiro Central \\ entre as Travessas A e B, 10, CEP: 78580-000, Alta Floresta-Brasil kimbarbieri@hotmail.com ${ }^{2}$ Universidade do \\ Estado de Mato Grosso - UNEMAT, Departamento de Ciências Biológicas, Campus de Alta Floresta, Rodovia MT \\ 208, KM 147, Jardim Tropical. CEP: 78580-000, Alta Floresta-Brasil *luciabraga@unemat.br ${ }^{3}$ Ecobio Consultoria \\ Agroambiental, Rua G5, 511, CEP: 78580-000, Alta Floresta-Brasil, marcilio.sousa@pq.cnpq.br ${ }^{4}$ Departamento \\ de Agronomia, Universidade Federal de Mato Grosso do Sul - UFMS, Estrada do Pasto Ruim, Zona rural, Caixa \\ Postal 112, CEP: 79560-000, Chapadão do Sul-Brasil
}

\begin{abstract}
RESUMO: Este estudo objetivou avaliar o desenvolvimento de Bixa orellana L. em condições de viveiro sob efeito da inoculação micorrízica e adubação fosfatada. As plantas foram cultivadas em sacos de polietileno com $0,18 \times 0,30 \mathrm{~m}$ e capacidade de $1,3 \mathrm{~kg}$ de substrato. O delineamento experimental utilizado foi inteiramente casualizado com seis tratamentos e trinta repetições. As dosagens de fósforo utilizadas foram $0,4.200$ e $8.400 \mathrm{~g} \mathrm{~m}^{-3}$ de substrato. O fungo micorrízico arbuscular (FMA) da espécie Glomus clarum, foi utilizado em metade dos tratamentos (com e sem micorrizas) com inoculação de $2 \mathrm{~g}$ do fungo. As avaliações ocorreram 30, 60, 90 e 120 dias após a emergência das plântulas. Determinou-se a massa seca de folhas, área foliar, massa seca total, razão de área foliar, área foliar específica, taxa assimilatória líquida, taxa de crescimento relativo e taxa de crescimento absoluto. O fungo micorrízico facilita a absorção de fósforo pelo urucum, atendendo a sua exigência em relação ao nutriente. A dose de fósforo de $4.200 \mathrm{~g} \mathrm{~m}^{-3} \mathrm{em}$ associação com FMA Glomus clarum ou $8.400 \mathrm{~g} \mathrm{~m}^{-3}$, com ou sem essa associação, são indicadas para o crescimento de plantas de urucum em viveiro, por promoverem adequadas respostas dos índices fisiológicos, contribuindo com seu desenvolvimento.
\end{abstract}

Palavras-chave: urucum, índices fisiológicos, desenvolvimento, micorriza, fósforo

ABSTRACT: Analyses of Bixa orellana L. growth under the effects of mycorrhizal inoculation and phosphate fertilization. This study aimed to evaluate the development of Bixa orellana $\mathrm{L}$. under nursery conditions and subjected to the effects of mycorrhizal inoculation and phosphate fertilization. The plants were grown in polyethylene bags with dimensions of $0.18 \times 0.30 \mathrm{~m}$ and capacity of $1.3 \mathrm{~kg}$ substrate. The adopted experimental design was completely randomized with six treatments and thirty replicates. The used phosphorus levels were $0,4.200$ and $8.400 \mathrm{~g} \mathrm{~m}^{-3}$ substrate. The arbuscular mycorrhizal fungus (AMF) of the species Glomus clarum was used in half of the treatments (with and without mycorrhizae) with inoculation of $2 \mathrm{~g}$ of the fungus. Evaluations occurred at 30, 60, 90 and 120 days after the emergence of seedlings. Leaf dry mass, leaf area, total dry mass, leaf area ratio, specific leaf area, net assimilation rate, relative growth rate and absolute growth rate were determined. The mycorrhizal fungus facilitates phosphorus uptake by annatto, fulfilling its requirement for the nutrient. The phosphorus level of $4.200 \mathrm{~g} \mathrm{~m}^{-3}$ in association with Glomus clarum or $8.400 \mathrm{~g} \mathrm{~m}^{-3}$, with or without this association, are indicated for annatto plant growth in nurseries since they promote appropriate responses of physiological indexes, contributing to the plant development.

Key words: annatto, physiological indexes, development, mycorrhiza, phosphorus

Recebido para publicação em 23/06/2008

Aceito para publicação em 03/03/2011

Rev. Bras. Pl. Med., Botucatu, v.13, n.2, p.129-138, 2011. 


\section{INTRODUÇÃO}

Variáveis de crescimento têm sido utilizadas para avaliar o comportamento das mudas de espécies florestais em relação ao fósforo e fungos micorrízicos arbusculares (FMA) em viveiro. A análise de crescimento descreve as condições morfofisiológicas da planta em diferentes intervalos de tempo, acompanhando assim seu crescimento, o qual, segundo Benincasa (2003), é o meio mais acessível e bastante preciso para avaliar o crescimento e mensurar a contribuição de diferentes processos fisiológicos sobre o comportamento vegetal.

Na produção de mudas de espécies florestais de qualidade, é indispensável que se tenha bom substrato, que é indicado, sobretudo pelas características físico-químicas, com boa estrutura, consistência, alta porosidade, alta capacidade de retenção e fornecimento de nutrientes e de água e que estejam inoculadas com fungos micorrízicos arbusculares - FMAs (Siqueira, 1996).

As respostas à aplicação de fósforo e inoculação com FMA em viveiro são relatadas a respeito de várias espécies (Carneiro, 1996; Caldeira, 1999; Resende, 1999; Fernandes et al., 2000; Minhoni \& Auler, 2003; Carneiro et al., 2004). Contudo, espécies com potencial em programas de reflorestamento devem ser estudadas quanto ao comportamento morfofisiológico em viveiro.

O fósforo é um macro-nutriente essencial para plantas em solos tropicais, sendo que vários autores descreveram o efeito no estabelecimento e crescimento de plantas, tanto tropicais quanto de climas temperados (Odum, 1988; Ricklefs, 2001; Raven et al., 2001; Gliessman, 2001; Primavesi, 2002).

As simbioses mutualísticas de micorrizas favorecem 0 desenvolvimento de plantas, proporcionando maior absorção de nutrientes pelas raízes e evitando-se possíveis patógenos. Fungos micorrízicos são aqueles que através de relações simbióticas não patogênicas, trazem benefícios para as plantas. O fungo favorece a nutrição da planta e, em troca, proporciona energia e fatores de crescimento para o fungo micorrízico. A inoculação de mudas florestais com FMA pode otimizar a obtenção de nutrientes, principalmente fósforo (Souza et al., 2009).

O urucum (Bixa orellana L.) é uma planta originária de regiões de clima tropical úmido, sendo a exploração tida como nativa no Brasil (Almeida et al., 1985). A espécie apresenta múltiplos usos, sendo planta ornamental e medicinal, se caracterizando também como recuperadora de solos. Possui um dos poucos corantes de uso permitido pela Organização Mundial de Saúde, visto não ser tóxico. O urucum é uma espécie pioneira, característica da floresta amazônica, sendo as sementes condimentares e tinturiais, muito utilizada na indústria. Possui qualidades ornamentais e pela rapidez de crescimento pode ser plantada em composição com outras espécies em áreas degradadas de preservação permanente destinadas à recomposição da vegetação (Lorenzi,1998).

O presente estudo objetivou avaliar o desenvolvimento inicial de mudas de Bixa orellana $\mathrm{L}$. em substrato com adição de micorriza e diferentes dosagens de fósforo, visando determinar o comportamento em viveiro.

\section{MATERIAL E MÉTODO}

O experimento foi conduzido em viveiro no município de Carlinda - MT (localização, 0956'15"S e 5540'54'W) no período de novembro de 2006 a março de 2007.

Utilizou-se solo Argissolo Vermelho Amarelo distrófico e textura média (Embrapa, 1999). Para a coleta do solo da camada arável, descartaram-se os $20 \mathrm{~cm}$ iniciais da camada superior, sendo então utilizado o solo abaixo dessa, chamado de terra de barranco.

Foram retirados $0,88 \mathrm{~m}^{3}(80 \%)$ dessa terra, sendo misturada a $0,22 \mathrm{~m}^{3}$ areia (20\%), totalizando 1,10 $\mathrm{m}^{3}$ de substrato o qual foi esterilizado em autoclave a $120^{\circ} \mathrm{C}$ por 60 minutos, sendo posteriormente acondicionado em sacos plásticos, os quais foram lacrados e armazenados no Laboratório da Fundação Agro Ambiental da Amazônia (FUNAM), Alta Floresta MT. Uma amostra foi utilizada para análises químicas e físicas (Tabela 1). Não se realizou calagem neste experimento, visto que, os valores do $\mathrm{pH}(5,9)$ e saturação de bases $(51,5 \%)$ foram, os indicados para culturas perenes, que são respectivamente $\mathrm{pH}$ 6,0 e saturação de bases 50\% (Gonçalves \& Benedetti, 2000), assim considerado, ótimo.

O delineamento experimental utilizado foi inteiramente casualizado, com seis tratamentos e 30 repetições, totalizando 180 plantas, avaliadas aos 30 , 60,90 e 120 dias (épocas de coleta) após a emergência. Além destas, 40 plantas de cada tratamento foram utilizadas para determinação de área foliar e massa seca, sendo utilizadas 10 plantas a cada época de coleta.

TABELA 1. Características químicas da amostra de solo utilizado para a produção de mudas de urucum.

\begin{tabular}{|c|c|c|c|c|c|c|}
\hline \multirow{2}{*}{$\begin{array}{c}\mathrm{pH} \\
\mathrm{H}_{2} \mathrm{O}\end{array}$} & \multirow{2}{*}{$\begin{array}{l}\mathrm{MO} \\
\mathrm{g} \mathrm{dm}^{-3}\end{array}$} & \multirow{2}{*}{$\begin{array}{c}P \\
\mathrm{mg} \mathrm{dm}^{-3}\end{array}$} & K & $\mathrm{Ca}$ & $\mathrm{Mg}$ & $\mathrm{Al}$ \\
\hline & & & \multicolumn{4}{|c|}{$\mathrm{cmol}_{\mathrm{c}} \mathrm{dm}^{-3}$} \\
\hline 5,9 & 12 & 2,9 & 0,12 & 1,13 & 0,87 & 0,00 \\
\hline $\mathrm{H}+\mathrm{Al}$ & $\mathrm{T}$ & $S$ & $\mathrm{~V}$ & Argila & Silte & Areia \\
\hline \multicolumn{3}{|c|}{ - $\mathrm{cmol}_{\mathrm{c}} \mathrm{dm}^{-3}{ }^{-3}$} & (\%) & 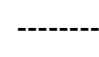 & $\mathrm{g} \mathrm{kg}^{-1}$ & \\
\hline 2,0 & 4,1 & 2,1 & 51,5 & 257 & 82 & 661 \\
\hline
\end{tabular}

Ke P: Menlich; Ca, Mg e Al: KCL 1N; H + Al: Acetato de Cálcio $\mathrm{pH}=7,0$

Rev. Bras. PI. Med., Botucatu, v.13, n.2, p.129-138, 2011. 
As dosagens de fósforo (superfosfato simples, contendo $18 \%$ de $\mathrm{P}_{2} \mathrm{O}_{5}$ ) utilizadas foram 0 , $4.200\left(765 \mathrm{~g} \mathrm{~m}^{-3}\right.$ de $\left.\mathrm{P}_{2} \mathrm{O}_{5}\right)$ e $8.400 \mathrm{~g} \mathrm{~m}^{-3}\left(1512 \mathrm{~g} \mathrm{~m}^{-3} \mathrm{de}\right.$ $\mathrm{P}_{2} \mathrm{O}_{5}$ ) de substrato. Apesar do fósforo utilizado neste experimento apresentar em torno de 10 a $12 \%$ de $S$ (Ralj et al., 1996), o que poderia influenciar em variações no crescimento do urucum, a análise do solo demonstra que a quantidade de enxofre no substrato é considerado ótimo, o que minimiza as variações. O fungo micorrízico arbuscular (FMA) da espécie Glomus clarum Nicolson \& Schenck foram multiplicadas em cultura-estoque em raízes de Brachiaria decumbens Stapf., cultivadas em vasos. O material (substrato de cultivo) contendo os esporos do fungo micorrízico arbuscular (FMA) foi adicionado no terço superior do substrato, coberto pelo mesmo, acondicionado nos sacos de polietileno e irrigados, posteriormente, duas vezes ao dia durante cinco dias antes da semeadura. A dose de inóculo, aplicada aos tratamentos, que receberam os fungos, foi de $2 \mathrm{~g}$ do substrato, contendo aproximadamente 120 esporos de FMA do referido cultivo. Os tratamentos utilizados foram denominados pelas letras $\mathrm{M}$ para micorrizas e $P$ para fósforo, sendo: MOPO - sem micorrizas e sem fósforo - controle; MOP1 - sem micorrizas e $4.200 \mathrm{~g}$ $\mathrm{m}^{-3}$ de fósforo; MOP2 - sem micorrizas e $8.400 \mathrm{~g} \mathrm{~m}^{-3}$ de fósforo; M1P0 - $2 \mathrm{~g}$ de FMA e $0 \mathrm{~g} \mathrm{~m}^{-3}$ de fósforo; M1P1 - $2 \mathrm{~g}$ de FMA e $4.200 \mathrm{~g} \mathrm{~m}^{-3}$ de fósforo; M1P2 $2 \mathrm{~g}$ de FMA e $8.400 \mathrm{~g} \mathrm{~m}^{-3}$ de fósforo.

Os tratamentos foram aplicados usando as diferentes dosagens de fósforo misturadas ao substrato com auxílio de enxada sobre encerado de plástico em ambiente coberto, sendo posteriormente acondicionados nos sacos de polietileno com dimensões de $0,18 \times 0,30$ $\mathrm{m}$ e capacidade de $1,3 \mathrm{~kg}$ de substrato.

As sementes de urucum (Bixa orellana L.) foram coletadas de árvores matrizes da região de Carlinda - MT em novembro de 2006 e acondicionadas em sacos de papel, mantidos em temperatura ambiente até o início dos ensaios.

As sementes de urucum foram desinfestadas em hipoclorito de sódio a 10\% por 30 minutos e lavadas, posteriormente, com água destilada em duas etapas, uma em imersão por 20 minutos e a outra em enxágue, quando, então, foram tratadas com o fungicida sistêmico Benomyl (Benlat 500) a 0,25\% da massa seca das sementes, sendo lavadas posteriormente com água destilada, no mesmo procedimento anterior e finalmente semeadas. O uso de Benomyl tem sido verificado em vários trabalhos de plantas em simbiose com fungos micorrizicos em nível de viveiro como forma prévia desinfestante (Bressan et al., 2001; Mello et al., 2008).

Foram semeadas três sementes em orifício de $1 \mathrm{~cm}$ de profundidade no substrato no interior dos sacos plásticos, sendo realizado o desbaste quando as plântulas atingiram $3,0 \mathrm{~cm}$ de altura, mantendo- se somente uma por saco. As plantas receberam adubação foliar na última semana de cada mês, sempre ao final do dia, na proporção de $1 \mathrm{~g}$ de sulfato de amônio $(21,21 \% N)$ por litro de água, equivalente a $212 \mathrm{mg}$ de $\mathrm{N} \mathrm{L}^{-1}$ num total de quatro litros, sendo em média de $4,71 \mathrm{mg} \mathrm{planta}^{-1}$ de $\mathrm{Naos} 30$ e 60 dias e, posteriormente, $2 \mathrm{~g}$ de amônia $(45 \% \mathrm{~N})$ por litro de

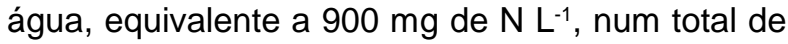
quatro litros, sendo em média, de $20 \mathrm{mg}^{\text {planta-1 }} \mathrm{de} \mathrm{N}^{-1}$ aos 90,120 e 150 dias.

O viveiro, construído em área aberta, foi coberto e cercado por sombrite $50 \%$ de radiação, sendo os sacos de polietileno depositados sobre bancada de madeira desinfestada com hipoclorito de sódio a 10\%.

As mudas foram irrigadas diariamente em duas etapas, manhã e tarde, por sistemas de micro aspersão até obter a saturação do substrato. Uma terceira irrigação ocorria quando necessário (por volta das 12:00 horas), mantendo o substrato úmido, evitando o ressecamento do mesmo e murchamento das mudas. A água foi coletada de lençol freático localizado em área acima do experimento e armazenada em caixa d' água com capacidade de 1 metro cúbico e elevada a três metros de altura para proporcionar pressão suficiente para a irrigação.

As avaliações foram realizadas em quatro coletas com dez plantas cada, a intervalos de trinta dias após a estabilização da emergência das plântulas (10 dias após semeadura). Determinou-se o comprimento da parte aérea e da raiz, diâmetro do coleto, número de folhas e a área foliar das plantas; em seguida foram separadas em caule, raiz, pecíolos e lâminas foliares, sendo acondicionados todos os órgãos em sacos de papel, colocados em estufa com circulação forçada de ar a temperatura de $65^{\circ} \mathrm{C} \pm 5^{\circ} \mathrm{C}$ até atingir massa seca constante. Após a secagem completa, o material foi pesado em balança analítica de até 0,001 $\mathrm{g}$ para determinação da massa seca.

Procedeu-se a estimativa dos seguintes índices fisiológicos, de acordo com Benincasa (2003): Massa seca de folhas (MSF): a massa seca de folhas $(\mathrm{g})$ correspondeu à massa das folhas de cada planta, em cada coleta, sendo definida como a média das massas.

Área foliar (AF): determinada com medidor de área foliar, modelo LI-300, e expressa em decímetros quadrados. A área foliar média foi definida como o resultado da soma das medidas individuais das áreas de todas as lâminas foliares de cada planta por repetição.

Massa seca total (MST): a massa seca total ( $\mathrm{g}$ ) correspondeu à soma das massas de todos os órgãos existentes, em cada coleta, sendo definida como a média das massas;

Razão de área foliar (RAF): a razão de área foliar $\left(\mathrm{dm}^{2} \mathrm{~g}^{-1}\right)$ expressa a área foliar útil para fotossíntese e foi definida como o quociente entre a área foliar

Rev. Bras. Pl. Med., Botucatu, v.13, n.2, p.129-138, 2011. 
(AF), área responsável pela intercepção de energia luminosa e a massa seca total (MST), resultado da fotossíntese:

$$
\mathrm{RAF}=\mathrm{AF} / \mathrm{MST}
$$

Área foliar especifica (AFE): é o componente morfológico e anatômico da RAF porque relaciona a superfície (AF) com a massa seca das folhas (MSF):

$$
\mathrm{AFE}=\mathrm{AF} / \mathrm{MSF}
$$

Taxa assimilatória líquida (TAL): a taxa assimilatória liquida $\left(\mathrm{g} \mathrm{dm}^{-2} \mathrm{dia}^{-1}\right)$ expressa a taxa de fotossíntese líquida, em termos de massa seca produzida. Foi obtida pela equação:

$$
T A L=\frac{P_{2}-P_{1}}{t_{2}-t_{1}} \cdot \frac{\operatorname{Ln~} A_{2}-\operatorname{Ln~} A_{1}}{A_{2}-A_{1}}
$$

Em que: $p=$ massa seca; $t=$ tempo em dias; 1 e 2 = amostras sucessivas; $L n=$ logarítmo neperiano; $A=$ amostra.

Taxa de crescimento relativo (TCR): a taxa de crescimento relativo $\left(\mathrm{g} \mathrm{g}^{-1} \mathrm{dia}^{-1}\right)$ de uma planta ou qualquer órgão da planta reflete o aumento da matéria orgânica em um intervalo de tempo, dependente do material préexistente. Essa taxa foi calculada pela equação:

$$
T C R=\frac{\operatorname{Ln} P_{2}-\operatorname{Ln} P_{1}}{t_{2}-t_{1}}
$$

Em que: $p=$ massa seca; $t=$ tempo em dias; 1 e 2 = amostras sucessivas; $L n$ = logarítimo neperiano.

Taxa de crescimento absoluto (TCA): a taxa de crescimento absoluto $\left(g\right.$ dia $\left.^{-1}\right)$ é a variação ou o incremento do crescimento em gramas por dia entre duas amostragens ao longo do ciclo. Essa taxa foi calculada pela equação:

$$
\text { TCA }=\frac{P_{2}}{t_{2}-t_{1}}
$$

Em que: $p=$ massa seca; $t=$ tempo em dias; 1 e 2 amostras sucessivas.

As variáveis foram analisadas pelo programa computacional ANACRES, de acordo com as especificações de Portes \& Castro Junior (1991) e os valores ajustados por equação de regressão em função do coeficiente de determinação ajustado.

\section{RESULTADO E DISCUSSÃO}

A massa seca das folhas (MSF) aumentou em todos os tratamentos durante o período de avaliação (Figura 1), comportamento esperado de acordo com o crescimento das plantas. Augostinho et al. (2008) também observaram esse comportamento em plantas de goiabeira (Psidium guajava L.).

A massa seca de folhas apresentou maiores valores, entre 90 e 120 dias, em plantas micorrizadas e com dosagens elevadas e médias fósforo (tratamentos M1P2 e M1P1 respectivamente) e em tratamento sem micorrizas, mas com a maior dosagem de fósforo aplicada (MOP2). O tratamento controle apresentou os menores valores de massa seca de folhas durante todo o período de avaliação. Matos et al. (2002) verificaram que plantas de bananeiras (cv. Nanicão) obtiveram maior massa seca de folhas quando adubadas e inoculadas com o FMA Glomus clarum.

Esses resultados corroboram com o de Balot et al. (2010) de que a aplicação de fósforo nas doses de 25, 50, 100 e $200 \mathrm{mg} \mathrm{kg}^{-1}$ e inoculação com FMA Glomus clarum proporcionaram incremento de massa seca para todas as variáveis da parte aérea de plantas de pinhão-manso (Jatropha curcas L.). Melloni et al. (2000) em trabalho com limoeiro-cravo (Citrus limonea (L.) Osbeck) observaram que em plantas inoculadas com Glomus interactides e doses de fósforo entre 50 e $250 \mathrm{mg} \mathrm{Kg}^{-1}$ foi maior o acúmulo de massa seca da parte aérea em relação ao controle. O comportamento da MSF indica que as

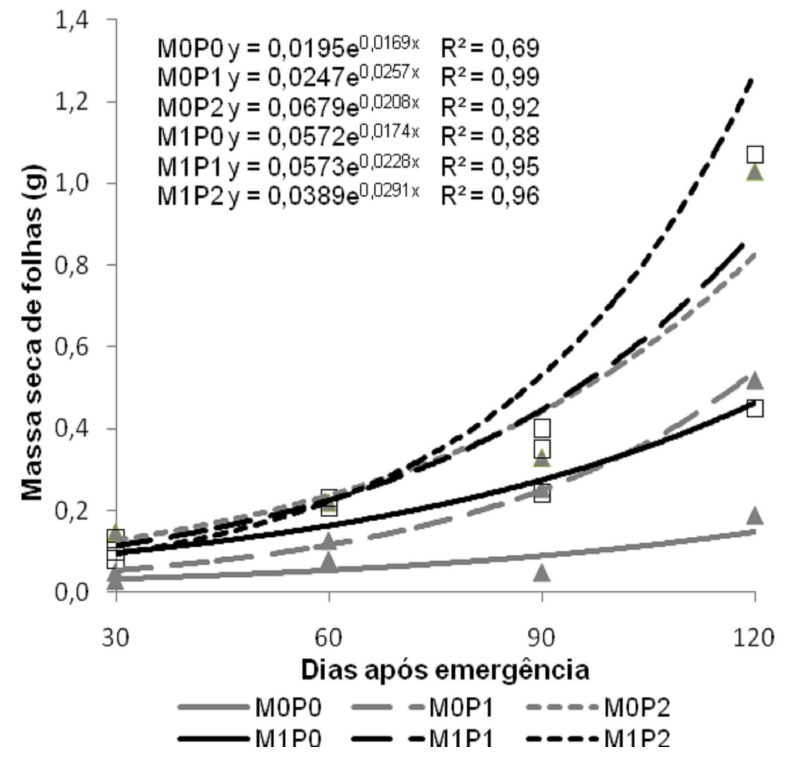

FIGURA 1. Massa seca de folhas (g) de plantas de urucum em função dos tratamentos.

dosagens de fósforo foram favoráveis ao aumento desta variável até 120 dias. Resende et al. (1999), em espécies pioneiras arbóreas (Lithraea molleoides e Schinus terebinthifolius), verificaram que dosagens de fósforo entre 100 e $800 \mathrm{mg} \mathrm{dm}^{-3}$ aumentaram em até $941 \%$ a produção de massa seca, em comparação ao controle. Corrêa et al. (2002) também afirmaram que o aumento de massa seca de folhas de aceloreira (Malpighia emarginata DC.) foi altamente dependente de fósforo.

A área foliar de urucum (Figura 2), durante 0 experimento, apresentou tendência a manter-se estável dos 30 aos 60 dias, ocorrendo aumento dos 60 aos 120 dias. As plantas submetidas aos tratamentos M1P2, M1P1 e M0P2 apresentaram maior aumento de área foliar aos 120 dias, sendo o controle (MOP0), o tratamento com menor desenvolvimento de área foliar. Anjos et al. (2005) verificaram em maracujazeiro doce (Passiflora edulis 
Sims f. flavicarpa Deg.) efeitos favoráveis de FMA e fósforo no desenvolvimento foliar das mudas.

Estes resultados observados para urucum corroboram com as observações de Siqueira \& Saggin Júnior (2001) que afirmaram que os FMAs promovem crescimento diferenciado entre as espécies nativas, com forte interação com fósforo. Para Pereira et al. (1996), os efeitos diretos da adubação fosfatada e das micorrizas arbusculares, são importantes para o estabelecimento de espécies arbóreas.

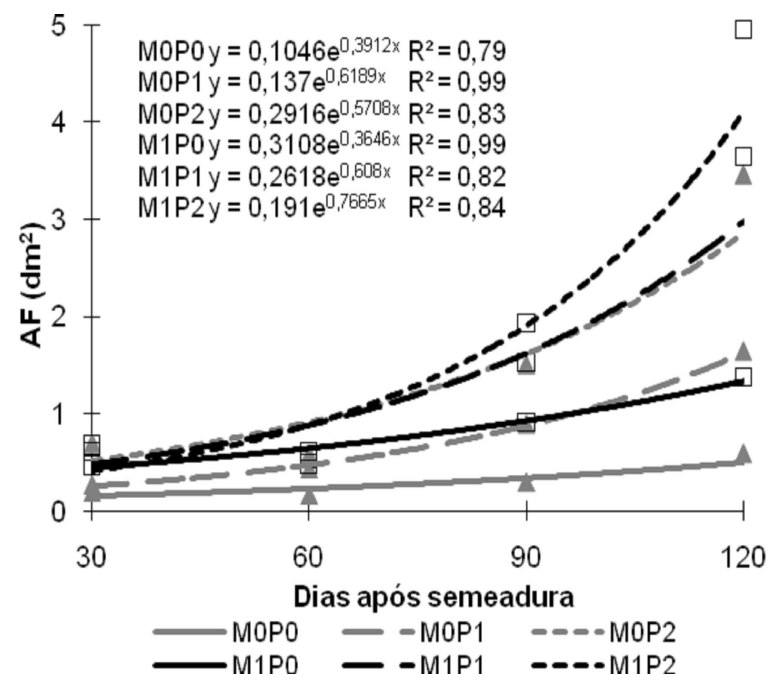

FIGURA 2. Área Foliar $\left(\mathrm{dm}^{2}\right)$ de plantas de urucum em função dos tratamentos.

$\mathrm{Na}$ Figura 3 verifica-se que a massa seca total (MST) de plantas de urucum apresentou discreta diminuição entre 30 e 60 dias, com posterior aumento, com exceção dos tratamentos M1P0, que incrementou biomassa dos 30 aos 120 dias, e MOP0 que estabilizou dos 30 aos 60 e aumentou de modo discreto dos 60 aos 120 dias após emergência. Os tratamentos M0P2, M1P1 e M1P2 apresentaram aumento acentuado da massa seca das plantas das plantas ao fim das avaliações, demonstrando que a associação do fósforo na dosagem de $4.200 \mathrm{~g} \mathrm{~m}^{-3}$ com o FMA Glomus clarum (tratamento M1P1) foi benéfica para o ganho de massa, já que o tratamento MOP1 (mesma dose de fósforo na ausência de FMA) promoveu menor incremento. Almeida et al. (1985) verificaram que todas as mudas de urucum inoculadas com fungos formadores de micorrizas do gênero Glomus, apresentaram maior massa seca da parte aérea em relação a testemunha não inoculada.

As curvas de produção de massa seca do urucum com dosagens de $8.400 \mathrm{~g} \mathrm{~m}^{-3}$ de fósforo em simbiose ou não com FMA (tratamentos MOP2 e M1P2, respectivamente) mostram que a elevação da dose de fósforo também promove resultados semelhantes ao observado no tratamento M1P1. Carneiro et al. (2002) observaram que plantas de alfafa (Medicago sativa) inoculadas com Glomus etunicatum

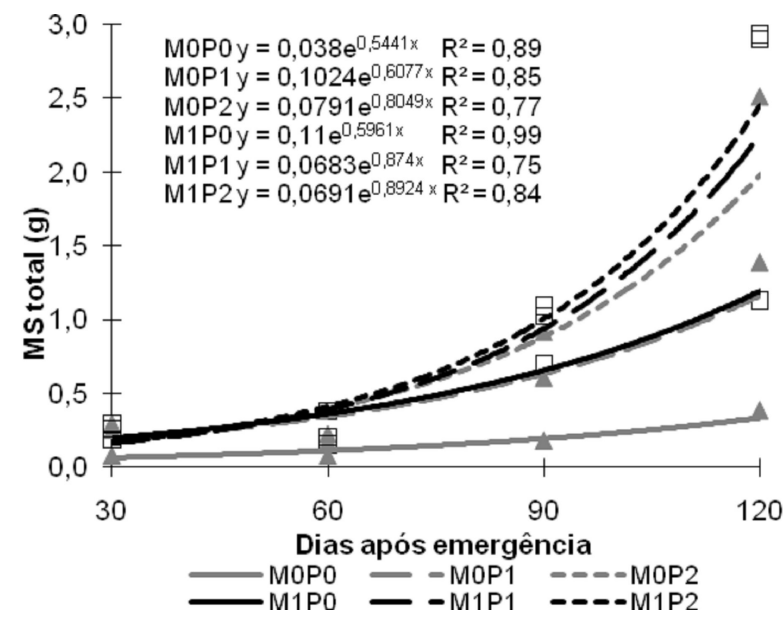

FIGURA 3. Massa seca total (g) de plantas de urucum em função dos tratamentos.

apresentaram maior massa seca total com aplicação das dosagens de 30,60, 120, 180 e $240 \mathrm{mg}$ de fósforo do que nos tratamentos sem inoculação. Nesta condição, as plantas apresentaram maiores valores de altura e produção de massa seca, sugerindo-se que para haver esse ganho em termos de biomassa, deve ter havido aumentos nas taxas de fotossíntese, ou seja, aumento da assimilação do $\mathrm{CO}_{2}$, o que poderia ser atribuído a presença benéfica do FMA no sistema, por favorecer aumento na absorção de micro e macronutrientes, em especial, nesse caso, de fósforo, elemento chave na produção de fotossintatos (Sena et al., 2004).

O benefício do FMA Glomus clarum à planta hospedeira parece estar relacionado com sua maior eficiência em absorver fósforo do solo e mantê-lo em elevados níveis nos tecidos das plantas de cedro (Cedrela fissilis) aos 120 dias, mostrando-se superior nas doses de 30, 480 e $960 \mathrm{mg} \mathrm{kg}^{-1}$ (Rocha et al., 2006).

Verificou-se para o urucum que não houve efeito inibitório do fósforo para a variável massa seca total e colonização FMA Glomus clarum e que a mesma foi benéfica ao incremento de biomassa, resultado semelhante ao descrito por Minhoni \& Auler (2003) em mamoeiro (Carica papaya L.).

O fato das plantas apresentarem maior massa seca total com o tratamento M0P2, comparando-se ao controle, implica que foi a dose de fósforo que influenciou no aumento da MST. Para Silva et al. (1998) os resultados dos tratamentos com inoculação de Glomus clarum, Gigaspora margarita, Glomus etunicatum e Scutellospora heterogama não diferiram significativamente entre si e em relação ao controle sem inoculação na massa seca da parte aérea de plantas de urucum. Chu et al. (2004) evidenciaram a necessidade de fósforo para 0 crescimento inicial de plantas. Resende et al. (1999) verificaram que aplicações de $800 \mathrm{mg} \mathrm{dm}^{-3}$ de fósforo 
isoladamente aumentou a massa seca total de aroeira (Lithraea molleioides) e jacaré (Piptadenia gonoacantha) em 941 e 596\% respectivamente em comparação ao controle. O fósforo é um elemento essencial à produção e acúmulo de biomassa (Primavesi, 2002) e na promoção de crescimento (Sena et al., 2004). Bressan et al. (2001) verificaram que a elevação da dose de fósforo até $200 \mathrm{mg} \mathrm{Kg}^{-1}$, promoveu o aumento de matéria seca da parte aérea de sorgo (Sorghum bicolor L.).

Na Figura 4 observa-se a razão de área foliar (RAF) de plantas de urucum no período de quatro meses de avaliação. Todos os tratamentos apresentaram redução da RAF dos 30 aos 120 dias após emergência, com exceção de M1P2 que estabilizou entre 90 e 120 dias e M1P0 que apresentou discreto aumento no mesmo período. Este comportamento de redução da RAF durante o período de avaliação, provavelmente, ocorreu pelo amadurecimento das folhas. Esse decréscimo coincide com os resultados de Barreiro et al. (2006) que referem RAF elevada no início do ciclo vegetativo, decrescendo com a maturação da planta, e de David et al. (2007) ao observaram que a RAF é elevada no início do ciclo vegetativo e decresce conforme amadurece devido à interferência de folhas superiores sobre as inferiores, indiferente de que espécies e soluções nutritivas utilizadas.

O crescimento da planta aumenta a interferência das folhas superiores sobre as inferiores, com tendência de diminuir a área foliar útil, a partir de certa fase (Benincasa, 2003). A mesma autora verificou comportamento semelhante em sorgo

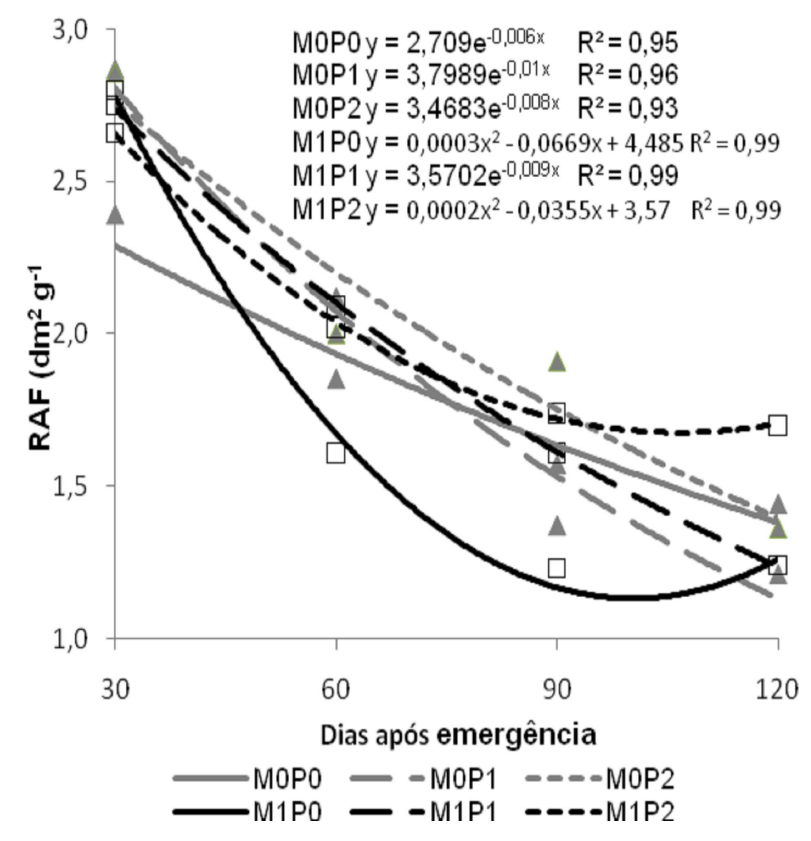

FIGURA 4. Razão de área foliar $\left(\mathrm{dm}^{2} \mathrm{~g}^{-1}\right)$ de plantas de urucum em função dos tratamentos.
(Sorghum bicolor) onde a RAF diminuiu do $13^{\circ}$ ao 111 o dias após semeadura corroborando com Urchei et al. (2000) que verificaram que a RAF do feijoeiro (Phaseolus vulgaris) aumentou até 30-37 dias após emergência, ou seja, os materiais da fotossíntese foram convertidos em folhas, ocorrendo posterior decréscimo da RAF promovido pelo desenvolvimento morfofisiológico da planta.

Estes resultados demonstram que aplicações de fósforo na dosagem de $8.400 \mathrm{~g} \mathrm{~m}^{-3} \mathrm{e}$ simbiose com FMA Glomus clarum (tratamento M1P2) favoreceram a RAF de plantas de urucum aos 120 dias. Rocha et al. (2006) verificaram maior crescimento em mudas de cedro (Cedrela fissilis) inoculadas com Glomus clarume aplicação de fósforo até $960 \mathrm{mg} \mathrm{kg}^{-1}$ aos 120 dias.

O resultado observado em plantas de urucum (Figura 4) provavelmente está relacionado ao fato da espécie necessitar de fósforo para seu crescimento, já que o fósforo é um dos elementos nutrientes (macronutriente) requerido, juntamente $\operatorname{com~N}, \mathrm{K}, \mathrm{Ca}$ e $\mathrm{Mg}$, em grande quantidade, para suprir as necessidades da planta (Larcher, 2006) e os FMA facilitarem a assimilação do mesmo (Minhoni \& Auler, 2003). Porém, segundo Siqueira (1994) o sucesso simbiótico depende da capacidade de absorção e translocação de fósforo de cada espécie, podendo diferentes espécies apresentar resultados diferentes a aplicações de fósforo, como verificado por Resende et al. (1999) no crescimento inicial de espécies florestais de diferentes grupos sucessionais em respostas a doses de fósforo, onde algumas espécies pioneiras responderam bem em dosagem zero e outras em dosagem de $800 \mathrm{mg} \mathrm{dm}^{-3}$ de fósforo.

O comportamento da área foliar especifica (Figura 5), revelou que plantas submetidas ao tratamento sem FMA e com $4.200 \mathrm{~g} \mathrm{~m}^{-3}$ de fósforo (MOP1) apresentaram maior AFE aos 30 dias. De maneira geral a AFE, em todos os tratamentos, diminuiu dos 30 aos 90 dias. Entre 90 e 120 dias, os tratamentos MOP0 e MOP1 tenderam a aumentar, quando comparados aos demais. Aos 120 dias todos os tratamentos apresentaram valores de AFE semelhantes. Esses resultados concordam com outros autores, como afirmou Benincasa (2003) que no início do desenvolvimento de plantas, os valores de AFE podem ser maiores, revelando folhas poucos espessas, com pouca matéria seca e pequena área foliar, mas conforme ocorre o desenvolvimento da cultura, aumenta a área foliar e massa seca das folhas, tendendo a diminuir os valores dessa variável no decorrer do experimento.

À medida que há desenvolvimento da área foliar, ocorre também acúmulo de massa seca nas folhas e como a AFE relaciona a superfície com a massa seca da folha, a tendência é a queda de seus valores logo após a primeira colheita, para 
estabilizar-se nas seguintes (Rodrigues, 1990). Para Ferreira (1996) o decréscimo da AFE indica aumento na espessura da folha resultante do aumento do número e do tamanho das células das folhas.

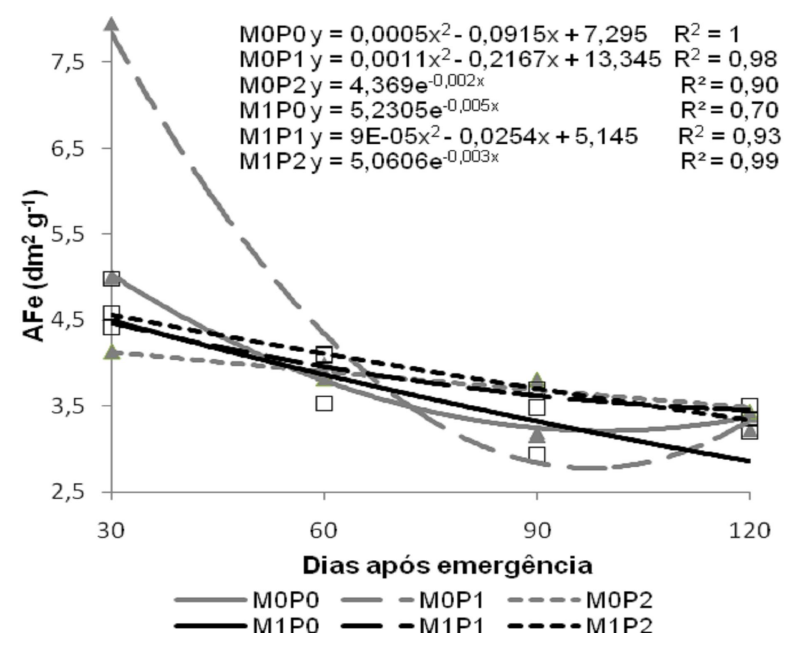

FIGURA 5. Área foliar especifica $\left(\mathrm{dm}^{2} \mathrm{~g}^{-1}\right)$ de plantas de urucum em função dos tratamentos.

A necessidade de fósforo em plantas de algodão (Gossypium hirsutum) foi relatada por Ferrari et al. (2005) aos 64 dias da emergência. A inoculação com o FMA e a adição de doses crescentes de fósforo, isoladamente, exerceram efeitos positivos significativos sobre o número de folhas de plantas de mamoeiro (Minhoni \& Auler, 2003).

Na Figura 6 observam-se as curvas da taxa assimilatória líquida ( $T A L$ ) de plantas de urucum onde revelam, de modo geral, aumento da TAL dos 30 aos 120 dias, com exceção de M1P0 que diminuiu dos 60 aos 120 dias e de M0P2 que também diminuiu de modo discreto dos 90 aos 120 dias após emergência.

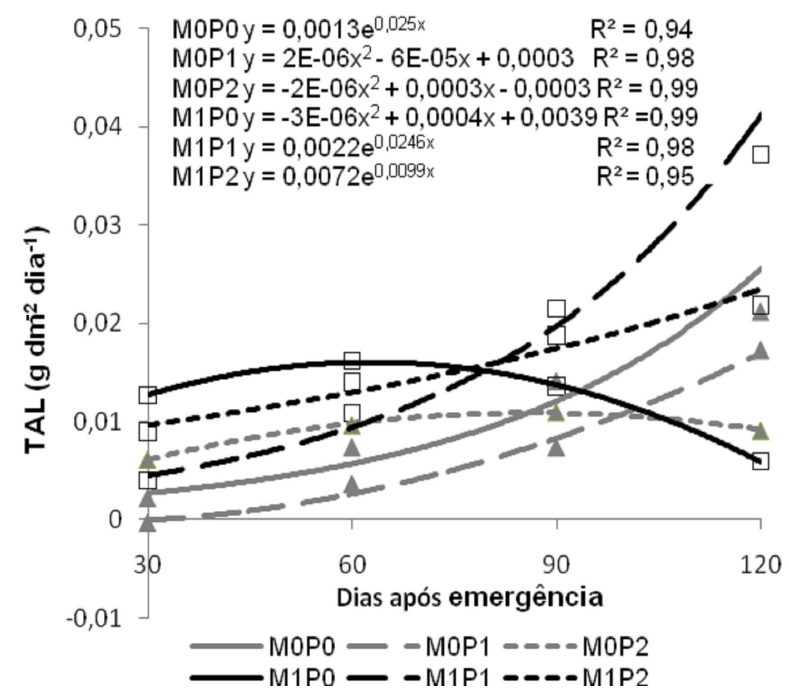

FIGURA6. Taxa assimilatória líquida $\left(\mathrm{g} \mathrm{dm}^{-2} \mathrm{dia}^{-1}\right) \mathrm{de}$ plantas de urucum em função dos tratamentos.
O aumento da TAL está relacionado ao acúmulo de biomassa, proporcionado pelo aumento da fotossíntese líquida devido ao aproveitamento da maior intercepção e fixação de energia luminosa por unidade de área. Benincasa (2003) se referiu a TAL, como sendo a taxa de fotossíntese liquida em termos de massa seca produzida por unidade de área foliar e por unidade de tempo, correlacionando então, área foliar e massa seca total. No presente trabalho, observou-se aumento das duas variáveis, área foliar e massa seca total, para todos os tratamentos dos 30 aos 120 dias.

Somente o tratamento M1P1 apresentou maior aumento da TAL, em relação ao controle aos 120 dias, indicando que a inoculação com FMA Glomus clarum e dosagem $4.200 \mathrm{~g} \mathrm{~m}^{-3}$ de fósforo favoreceram esta variável. O mesmo comportamento foi verificado por Rocha et al. (2006) na análise de crescimento de cedro (Cedrela fissilis) com aplicação de fósforo (doses entre 30 e $480 \mathrm{mg} \mathrm{kg}^{-1}$ ) e inoculação de FMA Glomus clarum, aos 180 dias. Illensser \& Paulilo (2002) verificaram que mudas de Euterpe edulis apresentaram maior taxa assimilatória líquida com aplicação de 10 e $20 \mathrm{mg}^{-1} \mathrm{~L}^{-3}$ de fósforo.

A diminuição da TAL nos tratamentos M1P0 e MOP2, comportamento esperado ao longo do tempo, possivelmente esteja relacionada ao fato de que as plantas aumentaram o número de folhas e também a área foliar, ocorrendo sombreamento das folhas inferiores. Tal comportamento foi descrito por Valmorbida et al. (2007) e Scavroni et al. (2009) em crescimento de Mentha piperita L. Urchei et al. (2000) afirmaram que a evolução da TAL com a idade da planta sugere diminuição progressiva desse parâmetro fisiológico ao longo dos diferentes estádios, evidenciando maiores valores durante o período vegetativo da cultura, com declínio mais acentuado, seguido de relativa constância da assimilação líquida na fase reprodutiva, com retomada de decréscimos sucessivos do final do estádio reprodutivo ao término do ciclo da cultura.

Segundo Rodrigues (1990), o comportamento da TAL pode ser divergente, influenciada por fatores climáticos, condução dos experimentos e pelas variações intra-específicas da TAL.

A tendência da taxa de crescimento relativo (TCR) de plantas de urucum (Figura 7) é crescente dos 30 aos 120 dias, com exceção do tratamento M1P0 que teve redução entre 30 a 60 dias aumentando posteriormente entre 60 e 120 dias.

A tendência da taxa de crescimento relativo (TCR) de plantas de urucum (Figura 7) é crescente dos 30 aos 120 dias, com exceção do tratamento M1P0 que teve redução entre 30 a 60 dias aumentando posteriormente entre 60 e 120 dias.

Benincasa (2003) afirmou que a TCR representa o aumento da massa seca de uma planta 
ou de qualquer um dos seus órgãos, em relação à massa seca existente no instante em que se inicia o período de observação e, Lima et al. (2007) afirmaram que variações da TCR podem ser consideradas normais uma vez que qualquer incremento ao longo de um determinado período está diretamente relacionado ao tamanho alcançado no período anterior, sendo que, segundo Urchei et al. (2000), a diminuição da TCR pode ser explicada pela elevação da atividade respiratória e pelo auto-sombreamento, cuja importância aumenta com a idade da planta. Tal redução da TCR é decorrente do crescimento da planta, que implica maior gasto com a manutenção das estruturas, resultando em maior respiração de manutenção (Pereira, 1989).

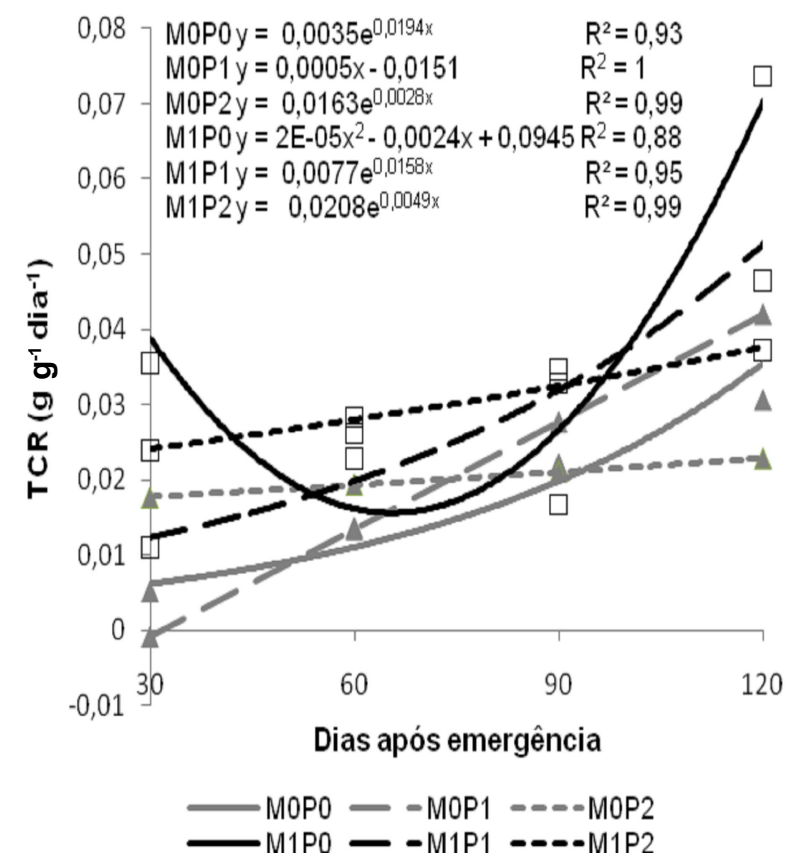

FIGURA 7. Taxa de crescimento relativo $\left(\mathrm{g} \mathrm{g}^{-1} \mathrm{dia}^{-1}\right)$ de plantas de urucum em função dos tratamentos.

Gava et al. (2001) verificaram que a TCR diminui à medida em que a planta cresce, devido, dentre outros fatores, ao aumento de competição intraespecífica pelos principais fatores ambientais responsáveis pelo crescimento vegetal, tais como luz e nutrientes.

Aos 120 dias, o tratamento M1P0 e M1P1 apresentaram maior TCR, indicando que há melhor probabilidade de sobrevivência de plantas de urucum em solos com média disponibilidade de fósforo e simbiontes que forneçam aporte através da extensão das hifas. De acordo com Moratelli et al. (2007), espécies que apresentam maior TCR garantem maiores condições de sobrevivência.

Estes resultados indicam que o urucum é um ótimo extrator de fósforo do solo e que as dosagens médias de fósforo com FMA (M1P0 e M1P1), deste trabalho, promoveram maiores valores de TCR. Carneiro et al. (2002) demonstraram que o FMA Glomus etunicatum promoveu aumento de crescimento da alfafa (Medicago sativa) em dosagens medianas de fósforo $\left(60,120\right.$ e $\left.180 \mathrm{mg} \mathrm{P} \mathrm{kg}^{-1}\right)$. Chu et al. (2004) também verificaram diferenças significativas no crescimento de mudas de guaruba (Vochysia maxima) inoculadas sem e com aplicação de fósforo. Almeida et al. (1985) afirmaram que todas as plantas de urucum inoculadas com fungos micorrizicos do gênero Glomus apresentaram diferenças significativas na massa seca da parte aérea em relação ao controle.

As curvas da TCA do urucum (Figura 8) evidenciam que as plantas de todos os tratamentos apresentaram discreta redução da TCA entre 30 e 60 dias e posterior aumento dos 60 aos 120 dias após emergência, com maior TCA os tratamentos M1P1, M1P2 e M0P2 aos 120 dias. O controle apresentou valores consideravelmente mais baixos. Os resultados se assemelham ao obtido por Chu et al. (2004), que verificaram crescimento de guaruba (Vochysia máxima) sob tratamentos com aplicação de fósforo, com e sem FMA. Minhoni \& Auler (2003) também verificaram crescimento de mudas de mamoeiro (Carica papaya) com aplicações isoladas de fósforo e inoculação de FMA, sendo o máximo crescimento promovido pela interação entre os fatores. Costa et al. (2001) observaram maior crescimento de plantas de aceroleira (Malpighia emarginata) quando inoculadas com os fungos Gigaspora margarita $e$ Glomus etunicatum.

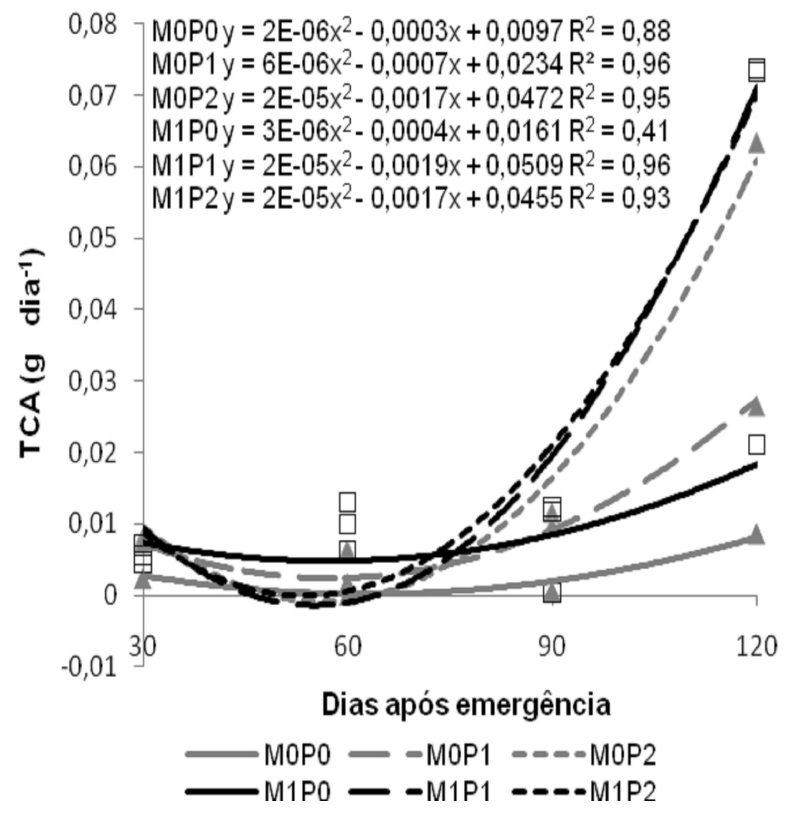

FIGURA 8. Taxa de crescimento absoluto ( $\mathrm{g} \mathrm{dia}^{-1}$ ) de urucum em função dos tratamentos. 
Verificou-se que, de maneira geral, as curvas da TCA apresentaram certa semelhança com MST demonstrando incrementos de biomassa máximos aos 120 dias, período máximo de avaliação deste trabalho. Estes resultados indicam que o urucum foi exigente em fósforo (com ou sem associação com FMA) para acúmulo de biomassa neste trabalho, o que também foi evidenciado pela TCA. Resende et al. (1999) verificaram que as espécies aroeira (Lithraea molleoides) e jacaré (Piptadenia gonoacantha) apresentaram maior crescimento com aplicação de $800 \mathrm{mg} \mathrm{dm}^{-3}$ de fósforo em relação ao controle. Fernandes et al. (2000) verificaram que houve crescimento da paineira (Chorosia speciosa) até a dosagem de $600 \mathrm{mg} \mathrm{dm}^{-3}$ de fósforo. Flores-Aylas et al. (2003) observaram que plantas de gravitinga (Solanum granuloso) inoculadas com Glomus etunicatum apresentaram maior crescimento com elevada dosagem de fósforo $\left(0,2 \mathrm{mg} \mathrm{L}^{-1}\right)$. Schumacher et al (2003) verificaram melhor crescimento das plantas de Pelthoporum dubium com doses entre 270 e $450 \mathrm{mg} \mathrm{kg}^{-1}$ de fósforo, sendo a espécie exigente a este nutriente.

\section{CONCLUSÃO}

O presente estudo permitiu concluir que:

- O fungo micorrízico facilita a absorção de fósforo pelo urucum, atendendo a sua exigência em relação ao nutriente.

- A dose de fósforo de $4.200 \mathrm{~g} \mathrm{~m}^{-3} \mathrm{em}$ associação com FMA Glomus clarum ou $8.400 \mathrm{~g} \mathrm{~m}^{3}$ com ou sem essa associação, são indicadas para o crescimento de plantas de urucum em viveiro, por promoverem adequadas respostas dos índices fisiológicos, contribuindo com o desenvolvimento.

\section{AGRADECIMENTO}

À CAPES pela concessão de bolsa ao primeiro autor. À FUNAM pela cedência das estufas e espaço físico.

\section{REFERÊNCIA}

ALMEIDA, R.T.; SARAIVA, J.A.B.; FREIRE, V.F. Efeito da inoculação de fungos micorrízicos vesículos arbusculares no desenvolvimento de mudas de urucu, Bixa orellana L. Ciências Agronômicas, v.16, n.2, p.65-7, 1985.

ANJOS, E.C.T. et al. Produção de maracujazeiro-doce micorrizadas em solo desinfestado e adubado com fósforo. Pesquisa Agropecuária Brasileira, v.40, n.4, p.345-551, 2005.

AUGOSTINHO, L.M.D. et al. Acúmulo de massa seca e marcha de absorção de nutrientes em mudas de goiabeira "Pedro Sato". Bragantia, v.67, n.3, p.577-85, 2008.

BALOTA, E.L. et al. Desenvolvimento e nutrição do pinhão-manso inoculado com fungos micorrízicos arbusculares em diferentes doses. In:CONGRESSO BRASILEIRO DE MAMONA, 4.; SIMPÓSIO INTERNACIONAL DE OLEAGINOSAS ENERGÉTICAS, 1., 2010, João Pessoa. Anais... Campina Grande: Embrapa Algodão, 2010. p.605-9.

BARREIRO, A.P. et al. Análise de crescimento de plantas de manjericão tratadas com reguladores vegetais. Bragantia, v.65, n.4, p.563-7, 2006.

BENINCASA, M.M.P. Análise de crescimento de plantas: noções básicas. Jaboticabal: Funep, 2003. 41p.

BRESSAN, W. et al. Fungos micorrízicos e fósforo, no crescimento, nos teores de nutrientes e na produção do sorgo e soja consorciados. Pesquisa Agropecuária Brasileira, v.16, n.2, p.315-23, 2001.

CALDEIRA, M.R. et al. Efeito de fungos micorrízicos arbusculares no desenvolvimento de duas leguminosas arbóreas. Ciência Florestal, v.9, n.1, p.63-70, 1999.

CARNEIRO, M.A.C. et al. Mycorrhizal fungi and superphosphate on growth of tropical woody species. Scientia Forestalis, n.50, p.21-36, 1996.

CARNEIRO, R.F.V. et al. Inoculação com fungos micorrízicos arbusculares em alfafa (Medicago sativa L.) em solos com doses crescentes de fósforo. Ciências Agrotécnicas, v.26, n.3, p.618-25, 2002.

CARNEIRO, M.A.C.; SIQUEIRAJ.O.; DAVIDE, A.C. Fósforo e inoculação com fungos micorrízicos arbusculares no estabelecimento de mudas de embaúba (Cecropia pachystachya Trec). Pesquisa Agropecuária Tropical, v.34, n.3, p.119-25, 2004.

CHU, E.Y.; YARED, J.A.G.; MAKI-ONUKI, H.J. Efeitos da inoculação micorrízica e da adubação fosfatada em mudas de Vochysia maxima Ducke. Revista Árvore, v.28, n.2, p.157-65, 2004.

CORREA, F.L.O. et al. Fósforo e zinco no desenvolvimento de mudas de aceroleira. Revista Brasileira de Fruticultura, v.24, n.3, p.793-6, 2002.

COSTA, C.M.C. et al. Influência de fungos micorrízicos arbusculares sobre o crescimento de dois genótipos de aceroleira (Malpighia emarginata DC.). Pesquisa Agropecuária Brasileira, v.36, n.6, p.893-901, 2001. DAVID, E.F.S.; BOARO, C.S.F.; MARQUES, M.O. Desenvolvimento e rendimento de óleo essencial de menta (Mentha x piperita L.) cultivada em solução nutritiva com diferentes níveis de fósforo. Biotemas, v.20, n.2, p.15-26, 2007.

EMBRAPA. Sistema brasileiro de classificação de solos. 2.ed. Brasília: Embrapa, 1999. 412p.

FERRARI, S. et al. Absorção de fósforo, na fase inicial de desenvolvimento de cultivares de algodão (Gossypium hirsutum L.). In: CONGRESSO BRASILEIRO DE ALGODÃO, 5., 2005, Salvador. Anais... Salvador: Embrapa, 2005.

FERREIRA, E. Ajustamento osmótico e análise de crescimento de plantas de milho (Zea mays L.), em função do nível de potássio e estresse hídrico. 1996. 112p. Tese (Doutorado em Botânica) - Curso de Pósgraduação em Ciências Biológicas, Universidade Estadual Paulista, Botucatu.

FERNANDES, L.A. et al. Crescimento inicial, níveis críticos de fósforo e frações fosfatadas em espécies florestais. Pesquisa Agropecuária Brasileira, v.35, n.6, p.1191-8, 2000. 
FLORES-AYLAS, W.W.; SAGGIN-JÚNIOR, O.J.O.; DAVIDE, A.C. Efeito de Glomus etunicatum e fósforo no crescimento inicial de espécies arbóreas em semeadura direta. Pesquisa Agropecuária Brasileira, v.38, n.2, p.257-66, 2003.

GAVA, G.J.C. et al. Crescimento e acúmulo de nitrogênio em cana-de-açúcar cultivado em solo coberto com palha. Pesquisa Agropecuária Brasileira, v.36, n.11, p.134754, 2001.

GLIESMANN, S.R. Agroecologia: processos ecológicos em agricultura sustentável. 2.ed. Porto Alegre: UFRGS, 2001. 653p.

GONÇALVES, J.L.M.; BENEDETTI, V. Nutrição e fertilização florestal. Piracicaba: IPEF, 2000. 427p.

ILLENSEER, R.; PAULILO, M.T.S. Crescimento e eficiência na utilização de nutrientes em plantas jovens de Euterpe edulis Mart. sob dois níveis de irradiância, nitrogênio e fósforo. Acta Botânica Brasílica, v.16. n.4, p.385-94, 2002.

LARCHER, W. Ecofisiologia vegetal. São Carlos: Rima, 2006. 531p.

LIMA, J.L.; PEIXOTO, C.P.; LEDO, C.A.S. Índices fisiológicos e crescimento inicial de mamoeiro (Carica papaya L.) em casa de vegetação. Ciência Agrotécnica, v.31, n.5, p.1358-63, 2007.

LORENZI, H. Árvores brasileiras: manual de identificação e cultivo de plantas arbóreas do Brasil. Nova Odessa: Plantarum, 1998. v.2. 381p.

MATOS, R.M.B.; SILVA, E.M.R.; BRASIL, F.C. Bragantia, v.61, n.3, p.277-83, 2002.

MELLO, A.H. et. al. Influência de substratos e fósforo na produção de mudas micorrizadas de Acacia mearnsii de Wild. Ciência Florestal, v.18, n.3, p.325-31, 2008.

MELLONI, R. et al. Fósforo adicionado e fungos micorrízzicos arbusculares no crescimento e nutrição mineral de limoeiro-cravo [Citrus limonia (L.) Osbeck]. Revista Brasileira de Ciências do Solo, v.24 p.767-75, 2000. MINHONI, M.T.A.; AULER, P.A.M. Efeito do fósforo, fumigação do substrato e fungo micorrízico arbuscular sobre o crescimento de plantas de mamoeiro. Revista Brasileira Ciência do Solo, v.27, n.5, p.841-7, 2003.

MORATELLI, E.M. et al. Efeito da disponibilidade da água e de luz na colonização micorrízica e no crescimento de Tabebuia avellanadae Lorentz Ex Griseb. (Bignoniaceae). Revista Árvore, v.31, n.3, p.555-66, 2007.

ODUM, E.P. Ecologia. Rio de Janeiro: Guanabara Koogan, 1988. 426p.

PEREIRA, A.R. Aspectos fisiológicos da produtividade vegetal. Revista Brasileira de Fisiologia Vegetal, v.1, n.2, p.139-42, 1989.

PEREIRA. E.G. et al. Efeitos da micorriza e do suprimento de fósforo na atividade enzimática e na resposta de espécies arbóreas ao nitrogênio. Revista Brasileira de Fisiologia Vegetal, v.8, n.1, p.59-66. 1996.

PRIMAVESI, A. Manejo ecológico do solo. São Paulo: Nobel, 2002. 548p.
PORTES, T.A.; CASTRO JUNIOR, L.G. Análise de crescimento de plantas: um programa computacional auxiliar. Revista Brasileira de Fisiologia Vegetal, v.3, n.1, p.53-6, 1991.

RAIJ, B.V. et al. Recomendação de adubação e calagem para o estado de São Paulo. 2.ed. Campinas: Instituto Agronômico, 1996. 100p.

RAVEN, P.H.; EVERT, R.F.; EICHHORN, S.E. Biologia vegetal. 6.ed. Rio de Janeiro: Guanabara Koogan, 2001. $906 \mathrm{p}$.

RESENDE, A.V. et al. Crescimento inicial de espécies florestais de diferentes grupos sucessionais a doses de fósforo. Pesquisa Agropecuária Brasileira, v.34, n.11, p.2071-81, 1999.

RICKLEFS, R.E. A economia da natureza. 5.ed. Rio de Janeiro: Guanabara Koogan, 2001. 503p.

ROCHA, F.S. et al. Dependência e resposta de mudas de cedro a fungos micorrízicos arbusculares. Pesquisa Agropecuária Brasileira, v.41, n.1, p.77-84, 2006.

RODRIGUES, J.D. Influência de diferentes níveis de cálcio, sobre o desenvolvimento de plantas estilosantes (Stylosanthes guyanensis (Aubl.) Swarts cv cook), em cultivo hidropônico. 1990. 97p. Tese (Livre docência em Fisiologia Vegetal) - Instituto de Biociências, Universidade Estadual Paulista, Botucatu.

SCHUMACHER, M.V.; CECONI, D.E.; SANTANA, C.A. Influência de diferentes doses de fósforo no crescimento de plantas de Peltophorum dubium (Sprengel) Taubert). Boletim de Pesquisa Florestal, n.47, p.99-114, 2003.

SCAVRONI, J. et al. Development of mint (Mentha piperita L.) grown on biosolids. Evaluation of productivity and essential oil content. Brazilian Archives of Biology and Technology, v.52, n.2, p.365-77, 2009.

SENA, J.O.A.; LABATE, C.A.; CARDOSO, E.J.B.N. Caracterização fisiológica da redução de crescimento de mudas de citrus micorrizadas em altas doses de fósforo. Revista Brasileira de Ciências do Solo, v.28, n.5, p.827-32, 2004.

SILVA, E.M.R. et al. Ocorrência e efetividade de fungos micorrízicos em plantas cultivadas. Seropédica: Embrapa Agrobiologia, 1998. 25p.

SIQUEIRA, J.O. Micorrizas arbusculares. In: ARAUJO, R.S.; HUNGRIA, M. (Eds). Microrganismos de importância agrícola. Brasília: EMBRAPA-SPI, 1994. p.151-94. (Documentos, 44)

SIQUEIRA, J.O. Micorrizas: forma e função. In: REUNIÃO BRASILEIRA SOBRE MICORRIZAS, 1.; 1995. Lavras, Anais... Lavras: FAEPE, 1996. p.5-32.

SOUZA, R.C. et al. Produção de mudas micorrizadas de Schinus terebinthifolius Raddi. em diferentes substratos. Floresta, v.39, n.1, p.197-206, 2009.

URCHEI, M.A.; RODRIGUES, J.D.; STONE, L.V. Análise de crescimento de duas cultivares de feijoeiro sob irrigação, em plantio direto e preparo convencional. Pesquisa Agropecuária Brasileira, v.35, n.3, p.497-506, 2000. 